\title{
Оптические свойства нанокристаллов CdS, легированных цинком и медью
}

\author{
() Ю.А. Ницук ${ }^{1}$, М.И. Киосе ${ }^{1}$, Ю.Ф. Ваксман ${ }^{1}$, В.А. Смынтына ${ }^{1}$, И.Р. Яцунский ${ }^{2}$ \\ ${ }^{1}$ Одесский национальный университет им. И.И. Мечникова, \\ 65082 Одесса, Украина \\ ${ }^{2}$ Университет им. Адама Мицкевича, \\ 61-712 Познань, Польша \\ E-mail: nitsuk@onu.edu.ua
}

(Получена 17 сентября 2018 г. Принята к печати 9 октября 2018 г.)

Коллоидным методом получены нанокристаллы $\mathrm{CdS}$. Легирование примесями $\mathrm{Zn}$ и Сu осуществлялось в процессе выращивания нанокристаллов. Исследованы спектры оптического поглощения и фотолюминесценции. По низкоэнергетическому смещению края фундаментального поглощения определена максимальная концентрация оптически активной примеси меди. Показано, что длинноволновая люминесценция нанокристаллов $\mathrm{CdS}$ и $\mathrm{CdS}: \mathrm{Zn}$ обусловлена оптическими переходами на донорно-акцепторных парах. $\mathrm{B}$ нанокристаллах $\mathrm{CdS}: \mathrm{Cu}$ оптическое поглощение и фотолюминесценция видимой области спектра обусловлены рекомбинационными переходами с участием основного состояния иона $\mathrm{Cu}_{\mathrm{Zn}}^{2+}$. ИК-поглощение и фотолюминесценция квантовых точек $\mathrm{CdS}: \mathrm{Cu}$ обусловлены внутрицентровыми переходами в пределах иона $\mathrm{Cu}_{\mathrm{Zn}}^{2+}$.

DOI: $10.21883 /$ FTP.2019.03.47291.8982

\section{1. Введение}

Полупроводниковые нанокристаллы группы $\mathrm{A}^{\mathrm{II}} \mathrm{B}^{\mathrm{VI}}$ находят сегодня все большее применение в современной электронике. Существующие методы синтеза позволяют получать нанокристаллы с узким распределением по размерам, заданной морфологией поверхности и высокой стабильностью. Возможность управления шириной запрещенной зоны и перестройкой длины волны люминесценции делают их применение перспективным в оптоэлектронике. Люминесцентные полупроводниковые наночастицы с широким спектром поглощения и ярко выраженными узкими пиками люминесценции в видимой и ближней ИК-областях спектра являются весьма перспективными для медицинской диагностики [1].

В ряду полупроводниковых нанокристаллов группы $\mathrm{A}^{\mathrm{II}} \mathrm{B}^{\mathrm{VI}}$ наиболее изученными являются нанокристаллы CdS. Преимуществами данного материала являются дешевый и простой способ получения, высокий квантовый выход излучения в видимой области спектра [2]. Многочисленные исследования люминесцентных свойств нанокристаллов сульфида кадмия показали, что в спектрах излучения доминируют широкие неэлементарные полосы излучения, локализованные в области $450-800$ нм $[3,4]$. Изменение размеров наночастиц, обусловленное варьированием различных технологических параметров (концентрации прекурсоров и стабилизаторов роста, рН и температуры среды и др.), приводит лишь к перераспределению интенсивности элементарных линий излучения при неизменном их спектральном положении.

Цель данной работы - поиск способа управления спектральным положением полос длинноволнового излучения нанокристаллов $\mathrm{CdS}$ путем легирования примесями цинка и меди, установление природы оптических и люминесцентных переходов в нелегированных нанокристаллах $\mathrm{CdS}$ и нанокристаллах $\mathrm{CdS}: \mathrm{ZnCdS}: \mathrm{Cu}$.

\section{2. Методика эксперимента}

В работе исследовались нанокристаллы сульфида кадмия, полученные химическим методом из коммерческих реактивов Beijing Reagent Company. В качестве источника ионов кадмия выступал хлорид кадмия, а ионов серы - сульфид натрия. При легировании медью или цинком в раствор 10\% хлорида кадмия добавлялся $10 \%$ раствор хлорида цинка или хлорида меди. Реакции синтеза наночастиц осуществлялись в 5\% растворе желатины и имели следующий вид:

$$
\begin{gathered}
\mathrm{CdCl}_{2}+\mathrm{Na}_{2} \mathrm{~S} \rightarrow \mathrm{CdS} \downarrow+2 \mathrm{NaCl}, \\
\mathrm{CdCl}_{2}+\mathrm{ZnCl}_{2}+\mathrm{Na}_{2} \mathrm{~S} \rightarrow \mathrm{CdS}: \mathrm{Zn} \downarrow+2 \mathrm{NaCl}+\mathrm{Cl}_{2} \uparrow \\
\mathrm{CdCl}_{2}+\mathrm{CuCl}_{2}+\mathrm{Na}_{2} \mathrm{~S} \rightarrow \mathrm{CdS}: \mathrm{Cu} \downarrow+2 \mathrm{NaCl}+\mathrm{Cl}_{2} \uparrow
\end{gathered}
$$

После удаления ненужных продуктов реакции коллоидный раствор наночастиц наносился на кварцевую подложку и помещался в термостат до высыхания полимерной пленки. Для исследований методами рентгеновской дифракции и сканирующей электронной микроскопии (СЭМ) раствор наносился на кремниевые подложки. На рентгеновских дифрактограммах доминирующими выявлены пики, которые соответствуют плоскостям (100), (002), (102), (110), (103) в CdS (рис. 1,a). Аналогичные плоскости были обнаружены в кристаллах $\mathrm{CdS}: \mathrm{Zn}$ (рис. $1, b)$ и кристаллах $\mathrm{CdS}: \mathrm{Cu}$ (рис. $1, c)$.

Для установления природы оптических и люминесцентных переходов в исследуемых нанокристаллах, 
Оптические характеристики нанокристаллов $\mathrm{CdS}, \mathrm{CdS}: \mathrm{Zn}, \mathrm{CdS}: \mathrm{Cu}$ в области края поглощения

\begin{tabular}{|c|c|c|c|c|}
\hline № образца & Тип нанокристалла & $E_{g}, \ni \mathrm{B}$ & $\Delta E_{g}$, мэВ & $R, \mathrm{HM}$ \\
\hline 1 & $\mathrm{CdS}, 0.01 \% \mathrm{CdCl}_{2}, 0.01 \% \mathrm{Na}_{2} \mathrm{~S}$ & 3.12 & 0.72 & 4.8 \\
\hline 2 & $\mathrm{CdS}, 0.02 \% \mathrm{CdCl}_{2}, 0.02 \% \mathrm{Na}_{2} \mathrm{~S}$ & 3.02 & 0.62 & 5.3 \\
\hline 3 & $\mathrm{CdS}, 0.03 \% \mathrm{CdCl}_{2}, 0.03 \% \mathrm{Na}_{2} \mathrm{~S}$ & 2.95 & 0.55 & 5.8 \\
\hline 4 & $\mathrm{CdS}, 0.1 \% \mathrm{CdCl}_{2}, 0.1 \% \mathrm{Na}_{2} \mathrm{~S}$ & 2.46 & 0.06 & 17.0 \\
\hline 5 & $\mathrm{CdS}: \mathrm{Zn}, 0.02 \mathrm{CdCl}_{2}+0.01 \% \mathrm{ZnCl}_{2}, 0.02 \% \mathrm{Na}_{2} \mathrm{~S}$ & 3.19 & 0.79 & 4.7 \\
\hline 6 & $\mathrm{CdS}: \mathrm{Zn}, 0.02 \mathrm{ZnCl}_{2}+0.02 \% \mathrm{CdCl}_{2}, 0.02 \% \mathrm{Na}_{2} \mathrm{~S}$ & 3.3 & 0.9 & 4.4 \\
\hline 7 & $\mathrm{CdS}: \mathrm{Cu}, 0.02 \% \mathrm{ZnCl}_{2}+0.001 \% \mathrm{CuCl}_{2}, 0.02 \% \mathrm{Na}_{2} \mathrm{~S}$ & 2.89 & 0.49 & 6.0 \\
\hline 8 & $\mathrm{CdS}: \mathrm{Cu}, 0.02 \% \mathrm{ZnCl}_{2}+0.005 \% \mathrm{CuCl}_{2}, 0.02 \% \mathrm{Na}_{2} \mathrm{~S}$ & 2.73 & 0.33 & 7.3 \\
\hline 9 & $\mathrm{CdS}: \mathrm{Cu}, 0.02 \% \mathrm{ZnCl}_{2}+0.01 \% \mathrm{CuCl}_{2}, 0.02 \% \mathrm{Na}_{2} \mathrm{~S}$ & 2.68 & 0.28 & 8.0 \\
\hline
\end{tabular}

определения среднего размера наночастиц и концентрации оптически активной примеси исследовались спектры оптической плотности и фотолюминесценции. С этой целью была отобрана серия образцов с разным количеством исходных и примесных компонентов (см. таблицу).

Спектры оптической плотности измерялись при помощи монохроматора МДР-6 с дифракционными решетками 1200 штр/мм для видимой области спектра и 600 штр/мм для ИК-области. В качестве приемника излучения для видимой области спектра использовал-

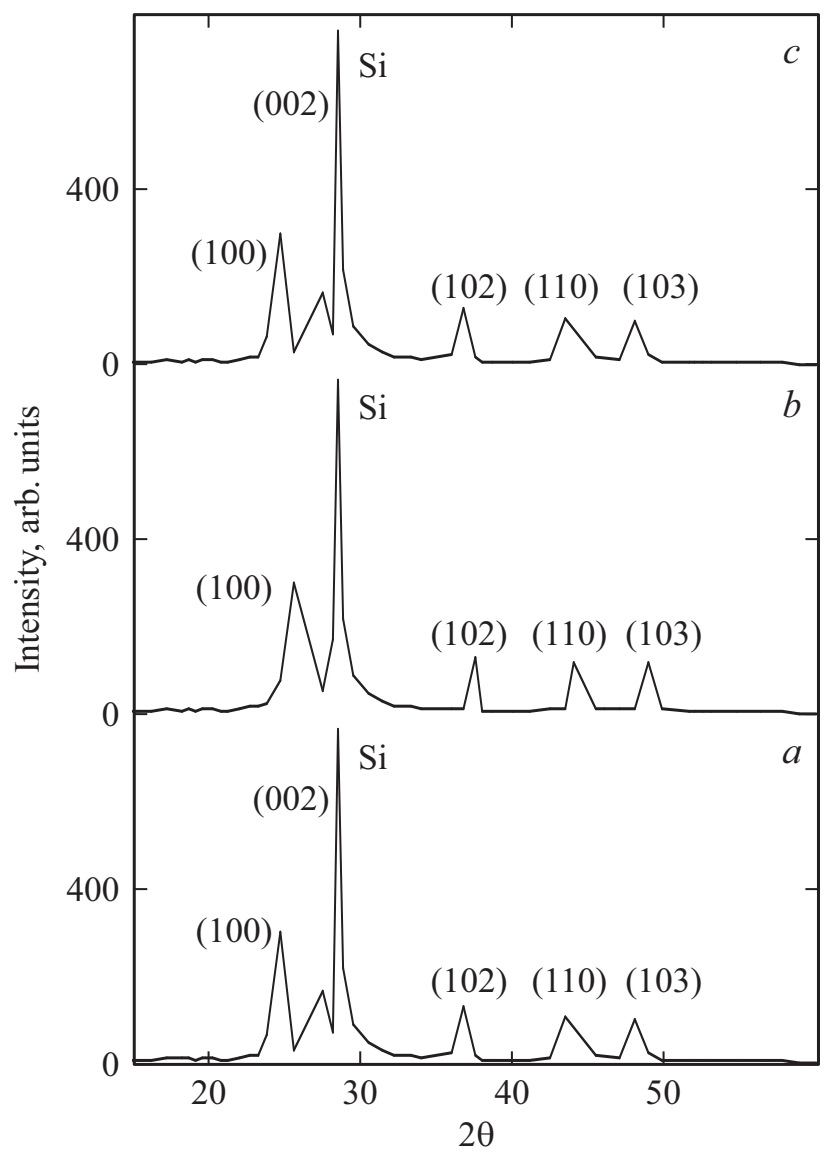

Рис. 1. Рентгенограммы нанокристаллов $\mathrm{CdS}(a), \mathrm{CdS}: \mathrm{Cu}(\boldsymbol{b})$ и $\mathrm{CdS}: \mathrm{Zn}(c)$. ся фотоэлектронный умножитель ФЭУ-100. Регистрация ИК-излучения осуществлялась ИК-фоторезистором ФР-1П, работающим в режиме регистрации по переменному току.

Спектры видимой фотолюминесценции измерялись на призменном спектрографе ИСП-51. Регистрация излучения проводилась фотоэлектронным умножителем ФЭУ-100. ИК-фотолюминесценция исследовалась на монохроматоре МДР-6 и регистрировалась ИК-фоторезистором. Возбуждение люминесценции осуществлялось светодиодами Edison Opto Corporation с максимумами излучения на $375,400,460,550$ и 640 нм и азотным импульсным лазером ИЛГИ-503 с длиной волны 331.7 нм. Исследования оптической плотности и фотолюминесценции проводились при комнатной температуре.

$\mathrm{B}$ нанокристаллах $\mathrm{CdS}: \mathrm{Cu}$ для выяснения природы центров, ответственных за люминесцентные и оптические свойства, проводились измерения в температурном диапазоне 293-423 К. В процессе измерений температура из указанного диапазона поддерживалась постоянной с помощью криостата.

\section{3. Исследование оптической плотности}

Спектры оптической плотности нелегированных нанокристаллов $\mathrm{CdS}$ представлены на рис. 2. Установлено, что уменьшение концентрации исходных хлорида кадмия и сульфида натрия с 0.1 до $0.01 \%$ приводит к смещению ширины запрещенной зоны в сторону больших энергий от 2.46 до 3.12 эВ, о чем свидетельствует изменение окраски коллоидных растворов от оранжевой до бесцветной.

По величине смещения ширины запрещенной зоны $\left(\Delta E_{g}\right)$ относительно объемного кристалла с использованием приближения эффективных масс по формуле из работы [5] оценивался средний радиус наночастиц

$$
R=\frac{h}{\sqrt{8 \mu \Delta E_{g}}} .
$$

Здесь $h-$ постоянная Планка; $\mu=\left(\left(m_{e}^{*}\right)^{-1}+\left(m_{h}^{*}\right)^{-1}\right)^{-1}$, где $m_{e}^{*}=0.19 m_{e}, m_{h}^{*}=0.8 m_{e}-$ соответственно эффек- 
тивные массы электрона и дырки в сульфиде кадмия, $m_{e}$ - масса свободного электрона; $\Delta E_{g}$ - разность между шириной запрещенной зоны в наночастице и объемном кристалле $\mathrm{CdS}$ (2.4 эB). Результаты расчетов представлены в таблице. Полученные результаты расчетов подтверждаются исследованиями, выполненными

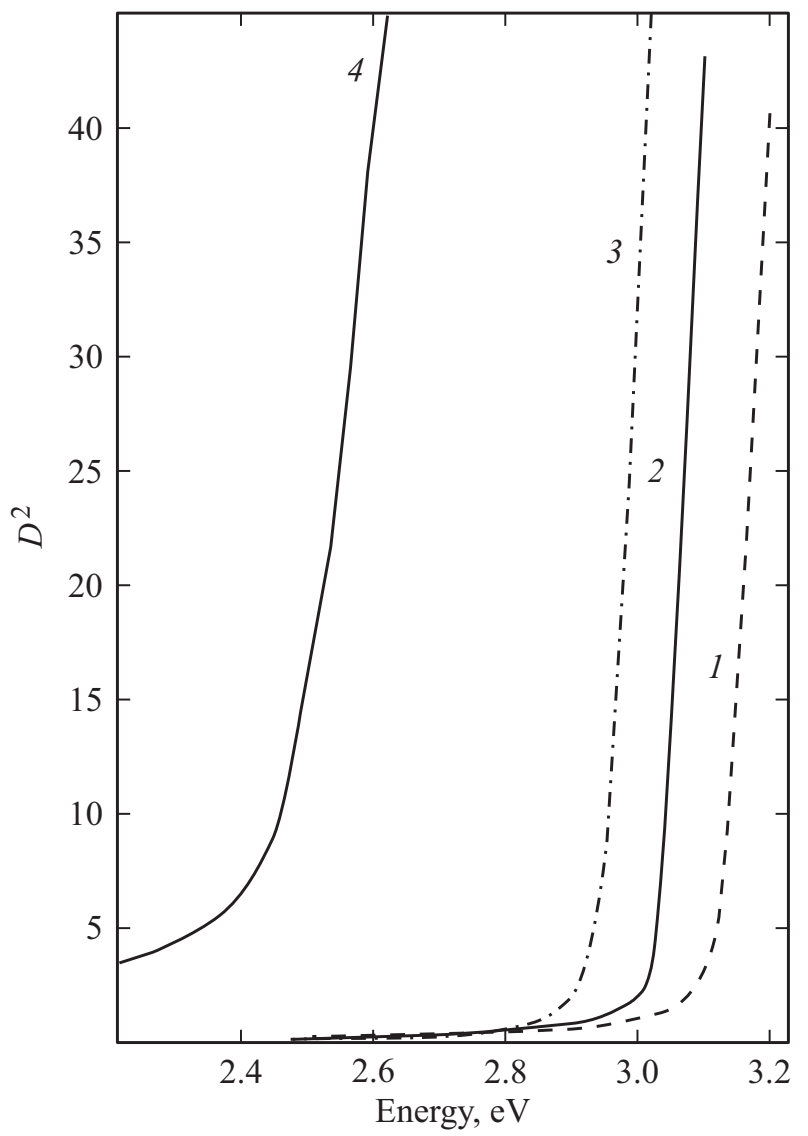

Рис. 2. Спектры оптической плотности нанокристаллов $\mathrm{CdS}$. Образец 1 (1), образец 2 (2), образцы 3 (3) и 4 (4).

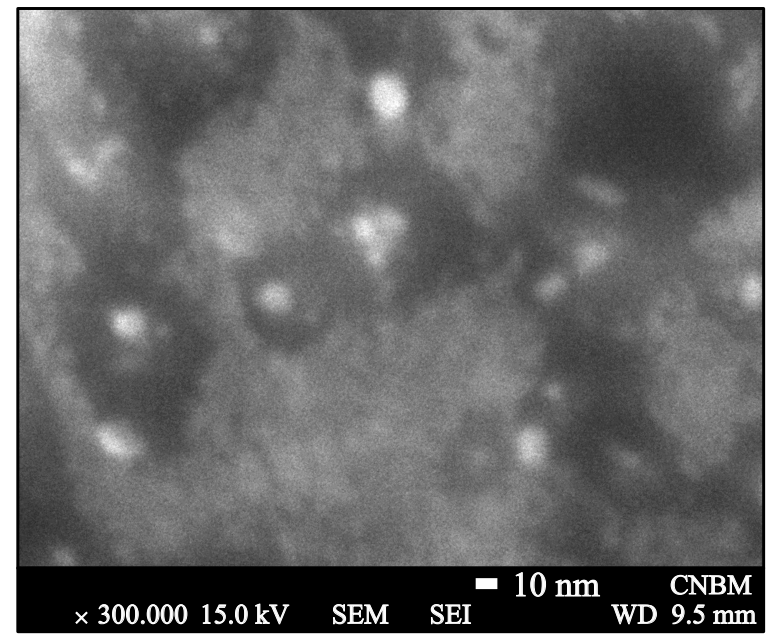

Рис. 3. СЭМ-изображения нанокристаллов $\mathrm{CdS}$ (образец 2).

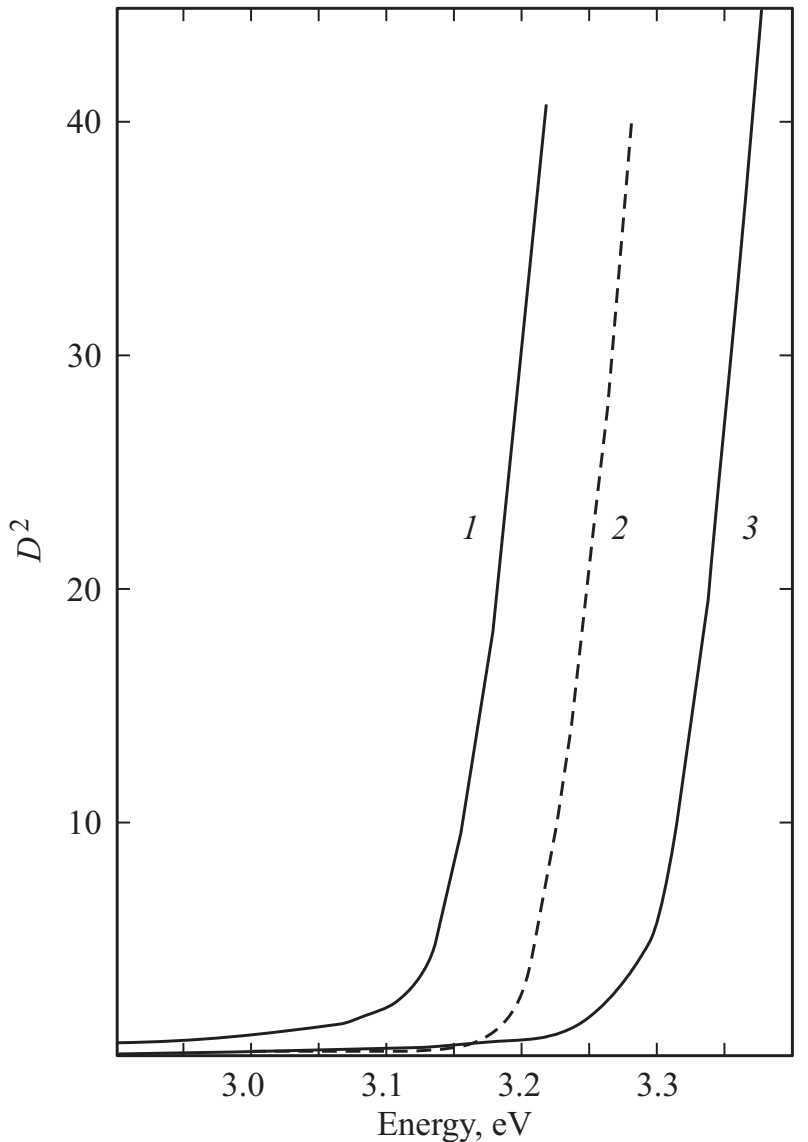

Рис. 4. Спектры оптической плотности нанокристаллов $\mathrm{CdS}(1)$ и $\mathrm{CdS}: \operatorname{Zn}(2,3)$. Образцы 1 (1), 5 (2) и 6 (3).

с помощью метода сканирующей электроннй микроскопии. СЭМ-изображения образца 2 представлены на рис. 3, где видно образование наночастиц размером 3-6 нм (рис. 3).

При легировании цинком край поглощения смещается в область больших энергий (рис. 4). При этом величина смещения возрастает с увеличением концентрации цинка. Аналогичное „синее“ смещение наблюдалось ранее в работе [6]. Увеличение ширины запрещенной зоны при легировании цинком может быть объяснено образованием тройного соединения $\mathrm{Cd}_{x} \mathrm{Zn}_{1-x} \mathrm{~S}$, что в работе [6] связано с увеличением периода решетки. На дифрактограммах сильно легированных нанокристаллов $\mathrm{CdS}: \mathrm{Zn}$ (рис. 1, c) наблюдается смещение дифракционных максимумов в сторону меньших углов.

В области 2.4-1.4 эВ в спектрах оптической плотности нанокристаллов $\mathrm{CdS}$ и $\mathrm{CdS}: \mathrm{Zn}$ каких-либо особенностей не обнаружено.

В нанокристаллах, легированных медью, наблюдается низкоэнергетическое смещение с увеличением концентрации $\mathrm{CuCl}_{2}$ (рис. 5). Данное смещение можно объяснить как увеличением размера частиц, так и межпримесным кулоновским взаимодействием, которое характерно для примесей переходных элементов [7-11]. 


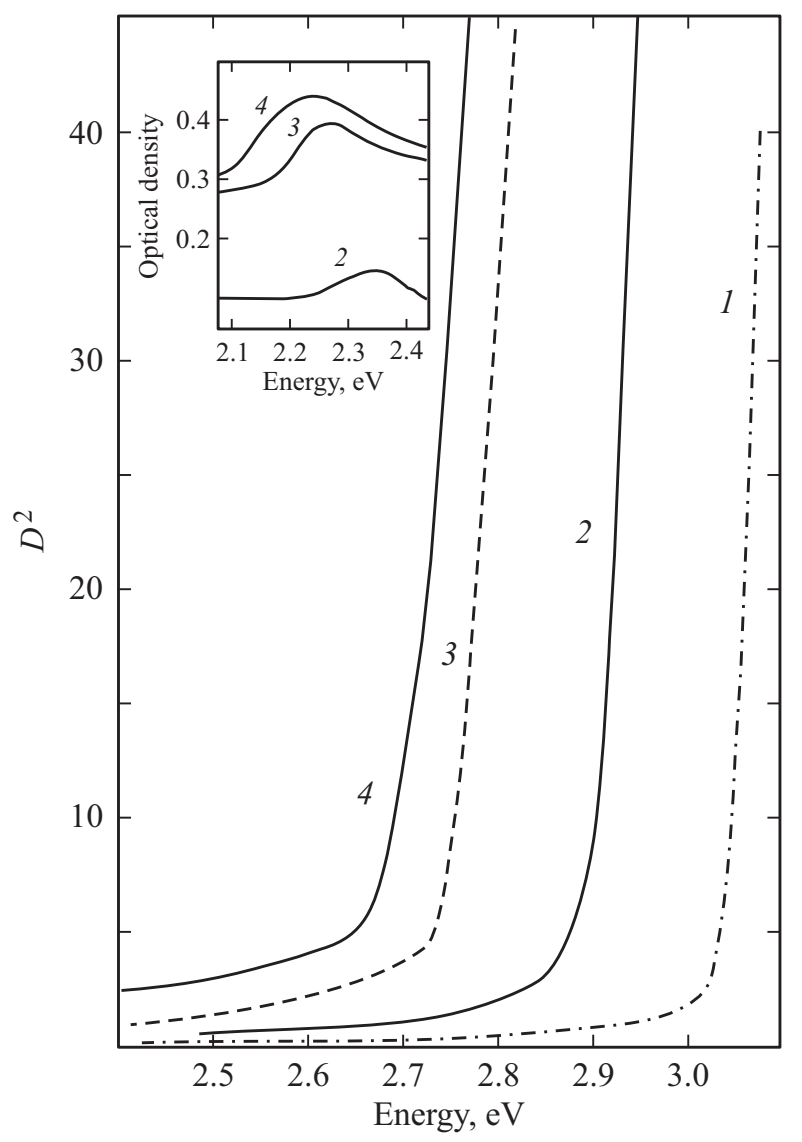

Рис. 5. Спектры оптической плотности нанокристаллов $\mathrm{CdS}(1)$ и $\mathrm{CdS}: \mathrm{Cu}(2-4)$. Образцы 3 (1), 7 (2), 8 (3) и 9 (4). На вставке - спектры оптической плотности нанокристаллов $\mathrm{CdS}: \mathrm{Cu}$ в видимой области.

С помощью соотношения [12]

$$
\Delta E_{g N}=2 \cdot 10^{5}\left(\frac{3}{\pi}\right)^{1 / 3} \frac{e N^{1 / 3}}{4 \pi \varepsilon_{0} \varepsilon_{s}},
$$

где $e-$ заряд электрона, $N$ - концентрация примеси меди в $\mathrm{cm}^{-3}, \varepsilon_{s}=8.9$ - статическая диэлектрическая проницаемость сульфида кадмия, по величине смещения ширины запрещенной зоны $\Delta E_{g N}$ между нелегированными наночастицами $\mathrm{CdS}$ (образец 2) и легированными нанокристаллами $\mathrm{CdS}: \mathrm{Cu}$ (образцы 7,8,9) рассчитывалась концентрация в исследуемых нанокристаллах $\mathrm{CdS}: \mathrm{Cu}$. Максимальная концентрация оптически активной примеси меди составила $10^{21} \mathrm{~cm}^{-3}$ в нанокристаллах, содержащих $0.01 \% \mathrm{CuCl}_{2}$. При уменьшении концентрации $\mathrm{CuCl}_{2}$ до 0.005 и до $0.001 \%$ концентрация оптически активной примеси меди уменьшается до $8 \cdot 10^{20}$ и $6 \cdot 10^{19} \mathrm{~cm}^{-3}$ соответственно. Высокие концентрации оптически активной примеси меди свидетельствуют об эффективном встраивании атомов меди в подрешетку кадмия при используемом методе легирования.

Также известно, что легирование полупроводниковых соединений примесями переходных элементов приводит к появлению линий поглощения в видимой и ИК обла- стях спектра. В исследуемых нанокристаллах $\mathrm{CdS}$ : Cu в видимой области наблюдается полоса примесного поглощения (рис. 5, см. вставку). Увеличение концентрации примеси меди приводит к увеличению поглощения в этой области, а максимум поглощения смещается в низкоэнергетическую область с 2.49 до 2.28 эВ. Величина смещения коррелирует с изменением ширины запрещенной зоны нанокристаллов $\mathrm{CdS}$ : Cu. При увеличении температуры нанокристаллов от 293 до $423 \mathrm{~K}$ полоса поглощения смещается в низкоэнергетическую область на 0.05 эВ. Такое смещение соответствует температурному изменению ширины запрещенной зоны CdS. Подобное поведение характерно для линий поглощения, обусловленных оптическими переходами типа примесный уровень $\rightarrow$ зона. По разнице между значениями ширины запрещенной зоны в нанокристаллах $\mathrm{CdS}: \mathrm{Cu}$ и максимумом линии поглощения определена глубина залегания примесного уровня меди от потолка валентной зоны, которая составила 0.4 эВ. Из сравнения с объемными кристаллами можно предположить, что такая глубина залегания соответствует основному состоянию ${ }^{2} T_{2}(D)$ иона $\mathrm{Cu}_{\mathrm{Zn}}^{2+}$.

В ИК-области спектры поглощения характеризуются линиями, локализованными на $0.86,1.12$ и 1.32 эВ (рис. 6, кривые 1-3). При увеличении концентрации ле-

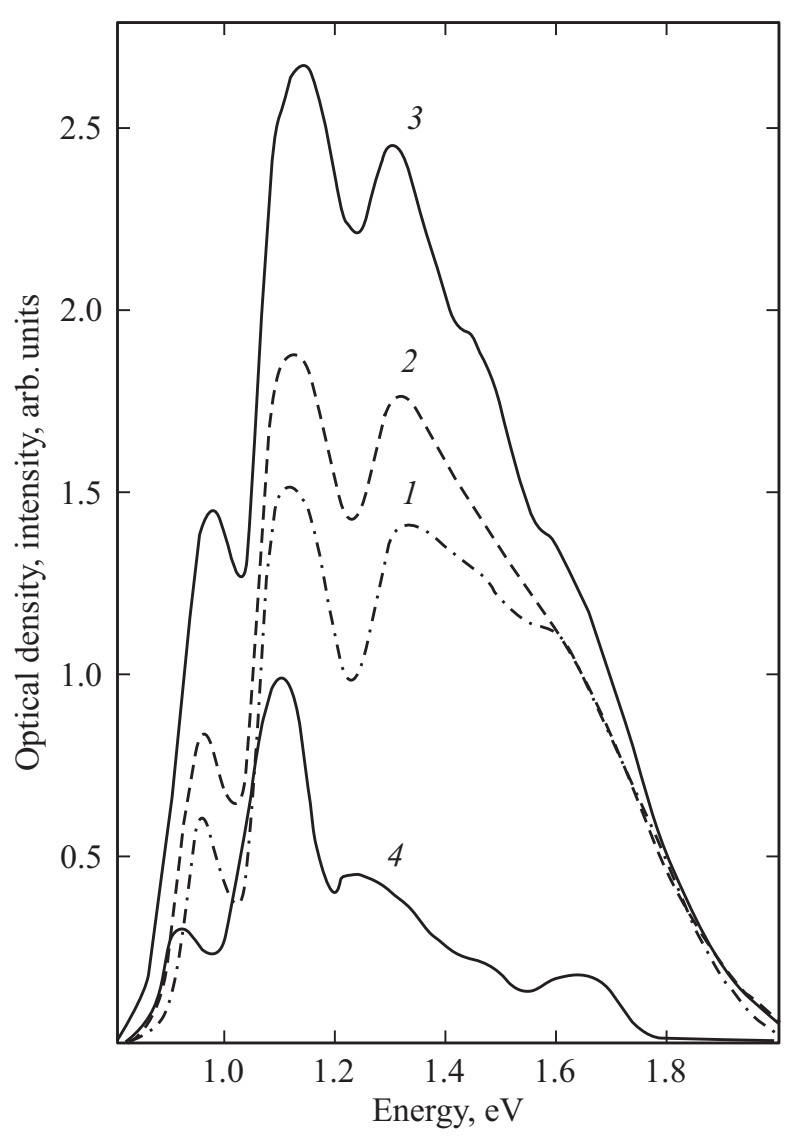

Рис. 6. Спектры оптической плотности (1-3) и фотолюминесценции (4) нанокристаллов $\mathrm{CdS}: \mathrm{Cu}$ в ИК-области. Образцы $7(1), 8(2,4), 9(3)$. 
гирующей примеси поглощение возрастало, а положение данных линий оставалось неизменным, неизменным оно оставалось при изменении температуры исследуемых образцов. Такое поведение характерно для линий внутрицентрового поглощения. Для иона $\mathrm{Cu}^{2+}$ в объемных кристаллах единственная линия внутрицентрового поглощения обусловлена переходами ${ }^{2} T_{2}(D) \rightarrow{ }^{2} E(D)$ [13].

Согласно данным работы [14], наблюдаемые в исследуемых нанокристаллах три линии поглощения могут быть объяснены тригональным искажением кристаллического поля, влияющим на величину кристаллического поля $D q$.

Другой причиной может быть влияние размеров кристаллитов на величину кристаллического поля $D q[15]$.

Мы предполагаем, что существование триплета можно объяснить образованием в результате реакции наночастиц $\mathrm{CdS}: \mathrm{Cu}$, в которых ионы $\mathrm{Cu}^{2+}$ находятся в различном окружении лигандов - тетраэдрическом, октаэдрическом, тригональном. Согласно данным работы [16], наименьшее расщепление имеет место в тераэдрическом окружении. И в нашем случае линия с минимальной энергией хорошо совпадает с тетраэдрически скоординированными линиями поглощения $\mathrm{Cu}^{2+}$ для объемных кристаллов CdS. Более высокоэнергетические линии соответствуют октаэдрическому и тригональному окружению. При этом тригональное окружение претерпевает значительные искажения, что проявляется в наличии серии слаборазрешенных линий поглощения в области 1.4-1.6 эВ. В подтверждении нашей гипотезы выступает присутствие дифракционных пиков, соответствующих разным кристаллическим плоскостям (рис. 1).

\section{4. Исследование фотолюминесценции}

Нелегированные нанокристаллы $\mathrm{CdS}$ при комнатной температуре характеризуются широкими неэлементарными полосами видимого излучения, локализованными в области 1.6-2.8 эВ (рис. 7). В кристаллах с малой концентрацией прекурсоров $(0.01-0.03 \%)$ при разложении на элементарные гауссовы составляющие выделяются шесть элементарных линий излучения, локализованных на 1.6, 1.8, 2.02, 2.12, 2.36 и 2.6 эВ соответственно (рис. 7). Высокоэнергетическая линия излучения смещал ась в область больших энергий с уменьшением концентрации прекурсоров. Установлена корреляция положения данной линии излучения с шириной запрещенной зоны. Это позволяет сделать предположение о экситонной природе этих линий излучения. Большое смещение $(0.2$ эВ) позволяет предположить наличие экситонов, связанных на точечном дефекте. Условия синтеза с малыми концентрациями прекурсоров кадмия позволяют предположить, что такими дефектами могут быть вакансии кадмия, выступающие акцепторами.

Положение остальных пяти линий излучения не зависело от изменения ширины запрещенной зоны нанокристаллов и совпадает с исследованными ранее линиями излучения на донорно-акцепторных парах в объемных

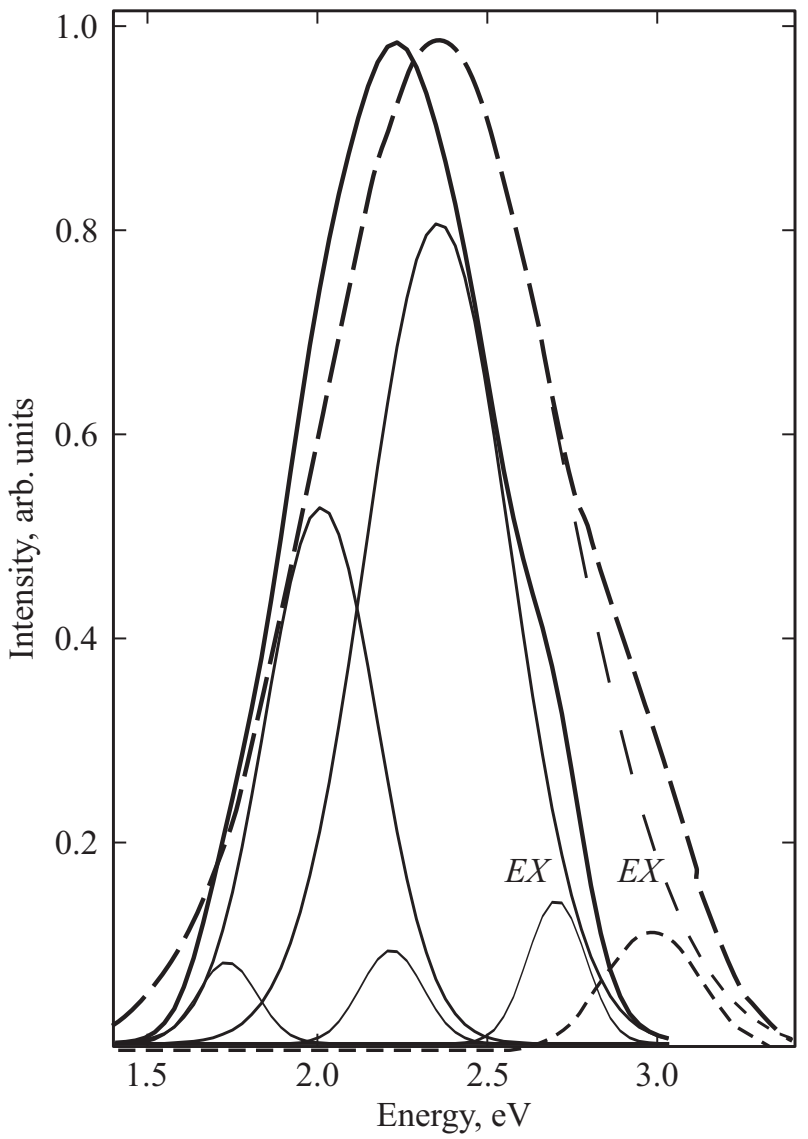

Рис. 7. Спектры фотолюминесценции нанокристаллов $\mathrm{CdS}$ (образец 3) (сплошная линия) и $\mathrm{CdS}: \mathrm{Zn}$ (образец 6) (пунктирная линия).

кристаллах $\mathrm{CdS}$. Линии излучения на 1.6 и 1.8 эВ обусловлены переходами с участием $\left(V_{\mathrm{S}}^{+}, V_{\mathrm{Cd}}^{2-}\right)^{-}$с различным расстоянием между парами [17]. Линии излучения на 2.02 и 2.12 эВ связываются с центрами $\left(\mathrm{Cd}_{i}^{+}\right.$, $\left.V_{\mathrm{Cd}}^{2-}\right)^{-}$с различным расстоянием между парами [18]. Линия излучения на 2.36 эВ связывается с нейтральными вакансиями $\left(V_{\mathrm{S}}^{+}, V_{\mathrm{Cd}^{-}}\right)^{*}[19]$.

При увеличении концентрации прекурсоров в нанокристаллах увеличивается доля межузельных атомов кадмия $\mathrm{Cd}_{i}^{+}$. Это подтверждается тем, что в таких образцах присутствуют только линии излучения на 2.02 и 2.12 эВ.

В кристаллах $\mathrm{CdS}: \mathrm{Zn}$ сохраняется структура и спектральный состав пяти линий излучения на донорноакцепторных парах. Преобладающей становится линия излучения на 2.36 эВ, а экситонная линия излучения вместе с краем поглощения смещается в область больших энергий (рис. 7). Подобное смещение линий экситонного излучения наблюдали ранее в работе [6].

Легирование медью в процессе выращивания нанокристаллов приводит к тушению линий излучения на донорно-акцепторных парах, а линия экситонного излучения смещается в область меньших энергий по сравнению с экситонной линией нелегированных нанокристал- 


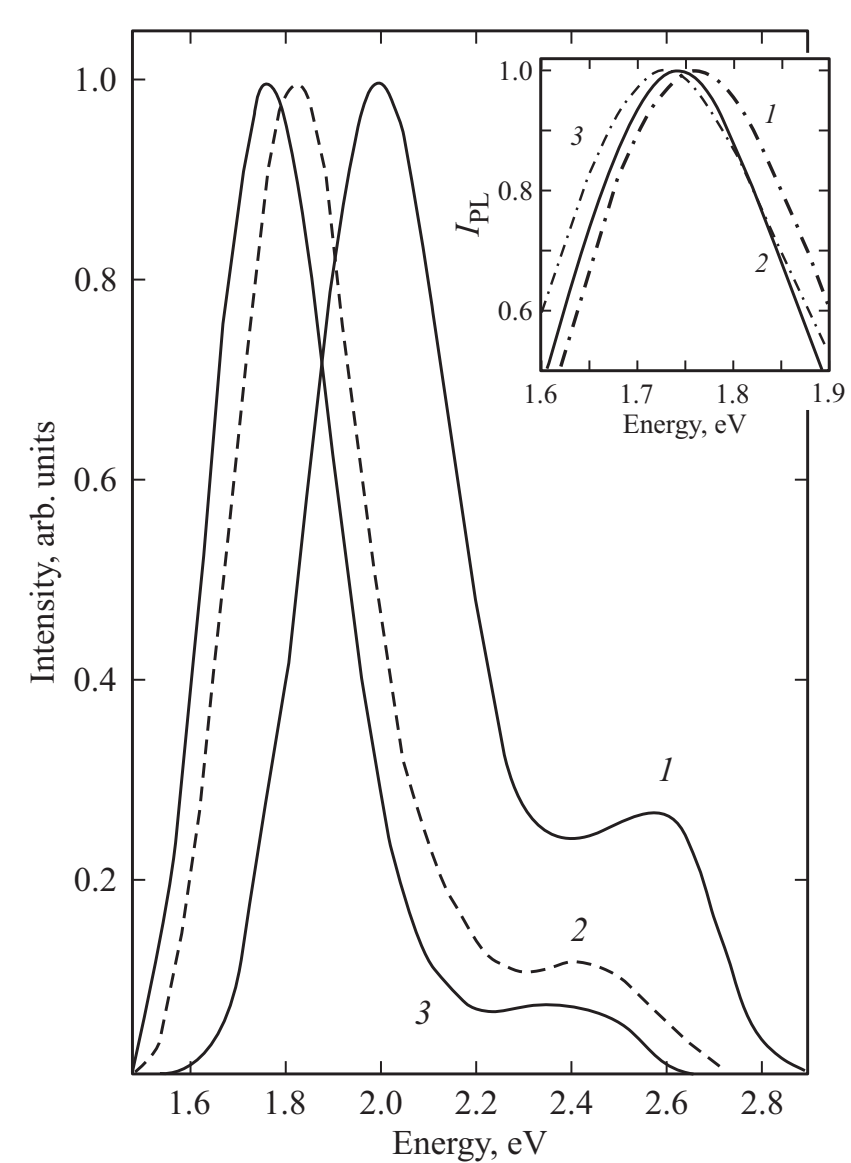

Рис. 8. Спектры фотолюминесценции нанокристаллов $\mathrm{CdS}: \mathrm{Cu}$. Образцы 7 (1), 8 (2), 9 (3). На ставке - спектры фотолюминесценции образца 9, измеренные при 293 (1), 353 (2) и $423 \mathrm{~K}(3)$.

лов $\mathrm{CdS}$ (рис. 8). Установлено уменьшение интенсивности этой линии с увеличением концентрации меди, что можно объяснить замещением вакансий кадмия атомами меди в процессе синтеза.

В длинноволновой области в нанокристаллах $\mathrm{CdS}: \mathrm{Cu}$ появляется полоса излучения, интенсивность излучения которой возрастала с увеличением концентрации меди. Максимум излучения смещался с 2 эВ при концентрации меди $0.001 \%$ до 1.78 эВ при концентрации $0.01 \%$ (рис. 8). Величина этого смещения совпадает с концентрационным изменением ширины запрещенной зоны и полосы поглощения в видимой области спектра (рис. 5) нанокристаллов $\mathrm{CdS}: \mathrm{Cu}$. Температурное смещение данных линий излучения из видимой области спектра в ближнюю ИК-область при нагревании от 293 до $423 \mathrm{~K}$ (рис. 8, см. вставку) соответствует температурному изменению ширины запрещенной зоны CdS. Максимальная интенсивность излучения наблюдается при возбуждении квантами света с энергиями 2.6 и 2.25 эВ, что хорошо перекрывается с полосами примесного поглощения в этих нанокристаллах. Это позволяет предположить, что центры, ответственные за поглощение и люминесценцию имеют идентичную природу. Согласно данным работы [20], излучение в этой области обусловлено переходами электронов из зоны проводимости на основное состояние ${ }^{2} T_{2}(D)$ иона $\mathrm{Cu}_{\mathrm{Zn}}^{2+}$. Величина стоксового смещения во всех образцах составила 0.5 эВ.

В средней ИК-области в нанокристаллах $\mathrm{CdS}$ : Cu при возбуждении квантами света с $E_{\mathrm{ex}}=2.25$ эВ наблюдается серия из трех линий излучения на $0.92,1.1$ и 1.24 эВ (рис. 6, кривая 4). Их положение оставалось неизменным при увеличении температуры образцов и концентрации примеси, а интенсивность возрастала с увеличением концентрации $\mathrm{CuCl}_{2}$ до $0.03 \%$. Такое поведение характерно для линий внутрицентрового излучения. Данные линии излучения коррелируют с исследованными ранее линиями поглощения (рис. 6, кривые 1-3). Величина стоксового смещения составила 30-60 мэВ.

Следует отметить, что с увеличением концентрации $\mathrm{CuCl}_{2}$ до $0.05 \%$ наблюдается концентрационное тушение ближней и средней ИК-фотолюминесценции.

\section{5. Заключение}

Проведенные исследования позволили сформулировать следующие выводы.

1. Изменением концентрации прекурсоров можно влиять на размер наночастиц и спектральный состав длинноволновой самоактивированной люминесценции нанокристаллов $\mathrm{CdS}$.

2. Добавление примеси цинка приводит к высокоэнергетичному смещению экситонной люминесценции $\mathrm{CdS}$. В самоактивированном излучении доминирующим становится зеленое свечение с максимумом излучения на 2.36 эВ.

3. Легирование медью приводит к низкоэнергетическому смещению края фундаментального поглощения и линий экситонного излучения $\mathrm{CdS}$. По величине смещения определена максимальная концентрация оптически активной примеси меди в нанокристаллах $\mathrm{CdS}$, которая составила от $6 \cdot 10^{19} \mathrm{~cm}^{-3}$ в нанокристаллах $\mathrm{CdS}$, содержащих $0.001 \% \mathrm{CuCl}_{2}$, до $10^{21} \mathrm{~cm}^{-3}$ в нанокристаллах $\mathrm{CdS}$, содержащих $0.01 \% \mathrm{CuCl}_{2}$.

4. Видимое излучение нанокристаллов $\mathrm{CdS}: \mathrm{Cu}$ характеризуется полосой примесного излучения, обусловленной излучательными переходами из зоны проводимости на основное состояние ${ }^{2} T_{2}(D)$ иона $\mathrm{Cu}_{\mathrm{Zn}}^{2+}$.

5. ИК-поглощение и фотолюминесценция нанокристаллов $\mathrm{CdS}: \mathrm{Cu}$ обусловлены внутрицентровыми оптическими переходами в пределах ионов $\mathrm{Cu}_{\mathrm{Zn}}^{2+}$, находящихся в разных типах окружения.

\section{Список литературы}

[1] С.В. Ремпель, А.Д. Левин, А.Ю. Садагов, А.А. Ремпель. ФТТ, 57 (6), 1088 (2015).

[2] В.И. Кочубей, Д.И. Кочубей, Ю.Г. Конюхова, И.В. Забенков, С.И. Татаринов, Е.К. Волкова. Опт. и спектр., 109 (2), $182(2010)$. 
[3] В.Г. Клюев, Фам Тхи Хан Мьен, Ю.С. Бездетко. Конденсированные среды и межфазные границы, 16 (1), 27 (2014).

[4] V. Smyntyna, B. Semenenko, V. Skobeeva, N. Malushin. Beilstein J. Nanotechnology, 5 (1), 355(2014).

[5] А.И. Гусев, А.А. Ремпель. Нанокристаллические материалы (М., Физматлит, 2000) с. 224.

[6] D.V. Korbutyak, S.V. Tokarev, S.I. Budzulyak, A.O. Kuryk, V.P. Kladko, Yu.O. Polishchuk, O.M. Shevchuk, H.A. Ilchuk, V.S. Tokarev. Phys. Chem. Sol. St., 14 (1), 222 (2013).

[7] Ю.Ф. Ваксман, В.В. Павлов, Ю.А. Ницук, Ю.Н. Пуртов, А.С. Насибов, П.В. Шапкин. ФТП, 39 (4), 401 (2005).

[8] Ю.Ф. Ваксман, Ю.А. Ницук, В.В. Яцун, А.С. Насибов, П.В. Шапкин. ФТП, 44 (4), 463 (2010).

[9] Yu.F. Vaksman, V.V. Pavlov, Yu.A. Nitsuk, Yu.N. Purtov, A.S. Nasibov, P.V. Shapkin. Func. Mater., 14 (4), 426 (2007).

[10] Ю.А. Ницук. ФТП, 48 (2), 152 (2014).

[11] I. Radevici, N. Nedeoglo, K. Sushkevich, D. Nedeoglo, H. Huhtinen, P. Paturi. Physica B: Condens. Matter, 503, 11 (2016).

[12] Ю.Ф. Ваксман, Ю.А. Ницук, Ю.Н. Пуртов, П.В. Шапкин. ФТП, 35 (8), 920 (2001).

[13] T. Telahun, U. Scherz, P. Thurian, R. Heitz, A. Hoffmann, I. Broser. Phys. Rev. B, 53 (3), 1274 (1996).

[14] S.Y. Wu, H.M. Zhang, H.N. Dong, X.F. Wang, Y.X. Hu. Phys. Chem. Minerals., 36, 483 (2009).

[15] Р. Шимкив, С. Свелеба, И. Карпа, И. Катеринчук, И. Куньо, О. Фицич. Тез. докл. конф. по физике полупроводников „Лашкаревские чтения“ (Киев, Украина, 2011) с. 59.

[16] Дж. Маррел, С. Кеттл, Дж. Теддер. Химическая связь (М., Мир, 1980) гл. 12, с. 249. [Пер. с англ.: J.N. Murrell, S.F.A. Kettle, J.M. Tedder. The Chemical Bond (Wiley, 1978) p. 249].

[17] И.Б. Ермолович, Г.И. Матвиевская, Г.С. Пекарь, М.К. Шейнкман. УФЖ, 18 (5), 732(1973).

[18] В.В. Горбунов, С.С. Остапенко, М.А. Танатар, М.К. Шейнкман. ФТТ, 23 (11), 3320(1981).

[19] И.Б. Ермолович, Г.И. Матвиевская, М.К. Шейкман. ФТП, $9(5), 1620$ (1975).

[20] V.E. Lashkarev, M.K. Sheinkman, I.B. Ermolovic. Proc. Int. Conf. II-VI compounds (N.Y., USA, 1967) p. 711.

Редактор А.Н. Смирнов

\section{Optical properties of CdS nanocrystals, doped with zinc and copper}

\author{
Yu.A. Nitsuk ${ }^{1}$, M.I. Kiose ${ }^{1}$, Yu.F. Vaksman ${ }^{1}$, \\ V.A. Smyntyna ${ }^{1}$, I.R. Yatsunskyi ${ }^{2}$ \\ ${ }^{1}$ Odessa I.I. Mechnikov National University, \\ 65082 Odessa, Ukraine \\ ${ }^{2}$ Adam Mickiewicz University, \\ 61-614 Poznan, Poland
}

\begin{abstract}
Nanocrystals of CdS were obtained by colloidall method. Doping with $\mathrm{Zn}$ and $\mathrm{Cu}$ impurities was carried out during the growth process. The optical absorption and photoluminescence spectra are investigated. The maximum concentration of the optically active copper impurity is determined from the low-energy shift of the fundamental absorption edge. It is shown that the longwavelength luminescence of $\mathrm{CdS}$ and $\mathrm{CdS}: \mathrm{Zn}$ nanocrystals is due to optical transitions at the donor-acceptor pairs. In $\mathrm{CdS}: \mathrm{Cu}$ nanocrystals, the optical absorption and photoluminescence of the visible spectral region are due to recombination transitions involving the ground state of the $\mathrm{Cu}_{\mathrm{Zn}}^{2+}$ ion. IR absorption and photoluminescence of $\mathrm{CdS}: \mathrm{Cu}$ quantum dots are due to intracenter transitions within the $\mathrm{Cu}_{\mathrm{Zn}}^{2+}$ ion.
\end{abstract}

